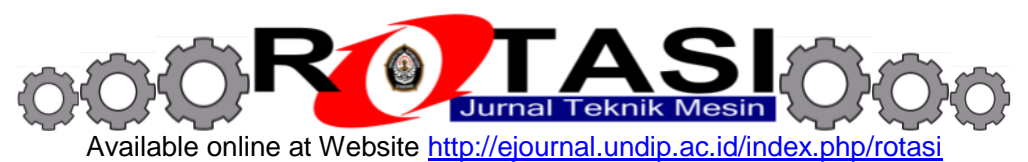

\title{
ANALISIS HIGH AXIAL VIBRATION PADA BLOWER 22K-102 REFORMER FORCE DRAFT FAN (FDF) - HYDROGEN PLANT
}

\author{
*Norman Iskandar, Muhammad Lazuardi Azzura \\ Departemen Teknik Mesin, Fakultas Teknik, Universitas Diponegoro \\ Jl. Prof. Sudharto, SH, Tembalang, Semarang 50275 \\ *E-mail: norman.mesin@gmail.com
}

\begin{abstract}
ABSTRAK
Blower 22K-102 FDF berfungsi untuk menggerakkan atau menghasilkan udara sekunder yang bertekanan tinggi, udara yang diambil FDF diambil dari luar, dalam perjalanan menuju boiler, udara tersebut dinaikkan suhunya oleh secondary air heater (pemanas udara sekunder) agar proses pembakaran bisa terjadi di boiler. Dalam proses perawatannya, kemudian dilakukan inspeksi terhadap blower 22K-102 FDF selama 2 minggu sekali, pada tanggal 21 januari 2016 terjadi kenaikan trending vibrasi pada bearing outboard yang diukur secara axial. Melalui metode defect frequency, yaitu dengan cara menggunakan data trending vibrasi dan spectrum vibrasi, kemudian dilakukan perhitungan terhadap tiap bagian sebuah bearing yaitu outerrace, innerrace, train, dan ball bearing, maka didapatkan hasil frekuensi dari metode tersebut, kemudian dilakukan plotting pada spektrum vibrasi, dari keempat bagian bearing tidak terdapat masalah kerusakan dikarenakan frekuensi kurang dari 1 kali RPM dan tidak menyentuh puncak RPM pada spektrum vibrasi, dimana pada tabel 1 dijelaskan bahwa hal tersebut dikarenakan mechanical looseness, dan kemudian dilakukan proses perbaikan yaitu tightening locknut dimana bagian ulir dari bearing dikencangkan, proses ini pada awalnya dilakukan pengecekan clearance pada bearing dengan feeler, dan didapatkan clearance bearing yaitu sebesar 0,2 $\mathrm{mm}$, hasil ini tidak sesuai dari standar clearance bearing yaitu sebesar 0,05 mm, maka dilakukan proses tightening locknut dan regreasing pada bagian bearing, dan didapatkan clearance yang sesuai standar bearing yaitu sebesar $0,05 \mathrm{~mm}$, maka dilakukan running dan didapatkan vibrasi pada bearing sudah dibawah alert high sebesar $4,53 \mathrm{~mm} / \mathrm{s}$ rms. Maka dari itu dapat diambil kesimpulan bahwa bearing tidak terjadi kerusakan pada tiap bagiannya dan terjadi kelonggaran pada clearance bearing dan vibrasi pada bearing kembali normal.
\end{abstract}

Kata kunci: Axial, Bearing, Blower, Clearance, Thightening Locknut

\section{PENDAHULUAN}

Blower 22K-102 FDF berfungsi untuk menggerakkan atau menghasilkan udara sekunder yang bertekanan tinggi, udara yang diambil FDF diambil dari luar, dalam perjalanan menuju boiler, udara tersebut dinaikkan suhunya oleh secondary air heater (pemanas udara sekunder) agar proses pembakaran bisa terjadi di boiler, fungsi dari blower FDF sangatlah penting, dimana ketika blower tidak berfungsi secara optimal produksi dari hidrogen akan berkurang sebesar $60 \%$.[1]

Blower mempunyai komponen-komponen utama, terdiri dari motor listrik kemudian rotasi dialirkan lewat shaft setelah itu bearing inboard dan juga bearing outboard dan yang terakhir adalah fan. Komponen-komponen penting ini setiap 2 minggu sekali dilakukan inspeksi, khususnya pada nilai vibrasi, karena dari proses pengukuran vibrasi bisa didapatkan kondisi dari suatu komponen.

4

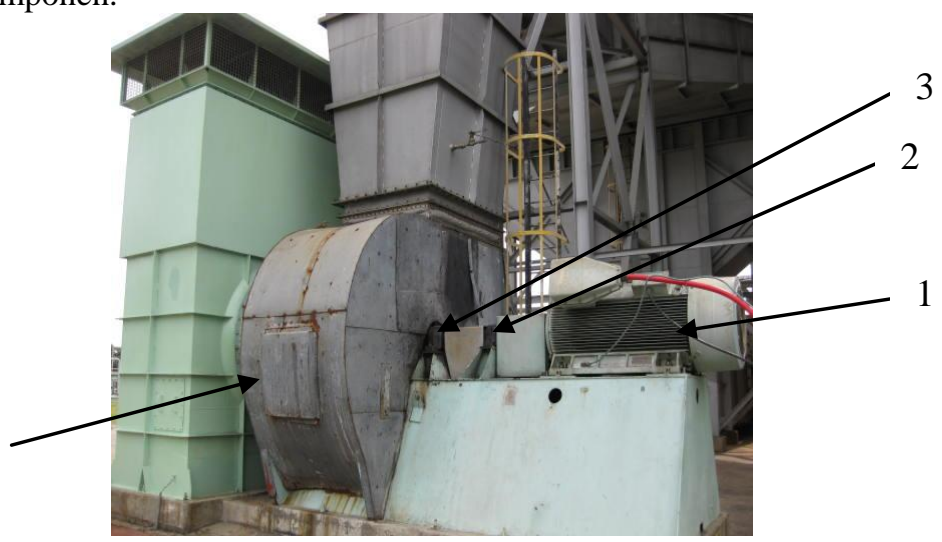

Gambar 1. Blower 22K-102 Force Draft Fan.

Dari gambar FDF diatas dijelaskan bahwa blower digerakkan oleh motor listrik yang ditunjukkan pada gambar 1, kemudian putaran dialirkan oleh shaft yang ditopang oleh 2 bearing, yaitu bearing inboard yang ditunjukkan oleh 
nomor 2, dan bearing outboard yang ditunjukkan pada nomor 3, sedangkan untuk blower itu sendiri ditunjukkan oleh nomor 4.

Pada hasil inspeksi tanggal 21 januari 2016 didapatkan data trending vibrasi diatas 4,53 mm/s rms yaitu sebesar $6,48 \mathrm{~mm} / \mathrm{s} \mathrm{rms}$, setelah didapatkan hasil trending vibrasi pada tanggal 21 januari 2016, maka inspection engineer melakukan inspeksi selama 2 hari sekali dan didapatkan hasil dengan trending vibrasi yang diatas 4,53 mm/s rms, kesimpulan bahwa bearing outboard yang diukur secara axial adanya masalah, maka dilakukan proses thightening locknut.

\section{MATERIAL DAN METODOLOGI}

Metodologi penelitian dapat lebih mudah untuk dijelaskan pada diagram alir dibawah ini yang terdiri dari langkah - langkah kerja sampai pada menyelesaikan penelitian.

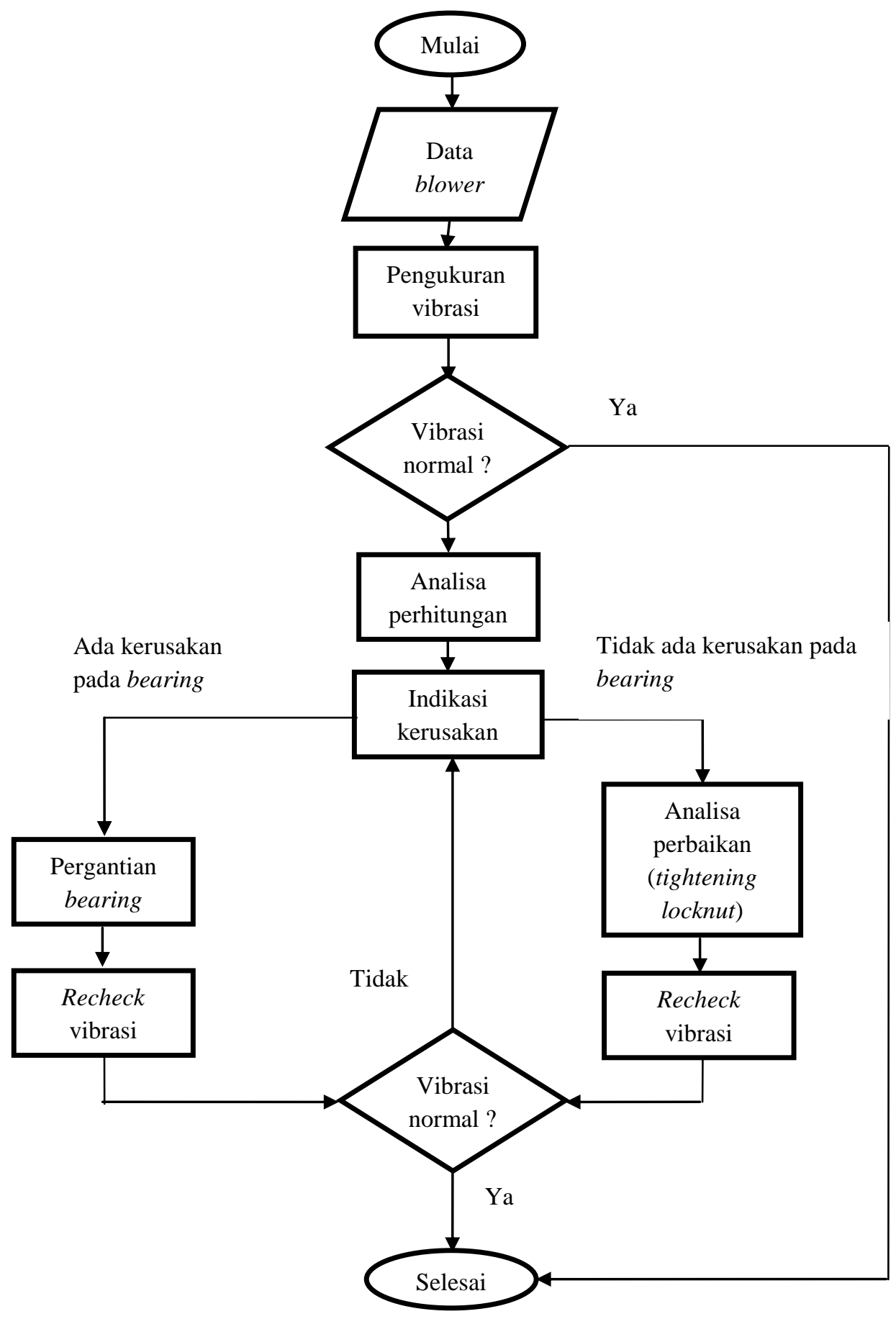

Gambar 2. Diagram alir analisa. 
Data trending vibrasi didapatkan atau diukur secara axial kemudian didapatkan spektrum vibrasi setelah itu dilakukan analisa perhitungan dengan teori defect frequency, hasil dari analisa perhitungan dengan defect frequency pada nantinya akan di-plotting terhadap spektrum vibrasi, kerusakan pada bearing dapat dilihat kesesuaian antara puncak dan hasil perhitungan dengan defect frequency, setelah selesai yaitu proses analisa perbaikan tightening locknut, recheck vibrasi dilakukan untuk memaastikan agar vibrasi sudah sesuai standar alert high.

\subsection{Analisis Trending Vibrasi dan Spektrum Vibrasi}

Yang dimaksud dengan trending vibrasi dan spektrum vibrasi disini adalah usaha menemukan masalah dan penyebabnya dengan mengkaji pola perbandingan besarnya amplitudo vibrasi pada semua frekuensi yang mungkin terjadi. Hasil ini digunakan untuk mengetahui dan juga mendiagnosa permasalahan yang terjadi pada sumber vibrasi, sudah terangkum dalam tabel 1. Macam-macam diagnosis yang akan didapat dari hasil spektrum vibrasi dilihat dari seberapa banyak frekuensi yang muncul dalam suatu spektrum.[3]

Tabel 1. Frekuensi Vibrasi dan Penyebabnya

\begin{tabular}{ll}
\hline \multicolumn{1}{c}{ Frekuensi dalam RPM } & \multicolumn{1}{c}{ Ruang lingkup } \\
\hline 1x RPM & Un-balance \\
& Excessive Bearing Clearance \\
2x RPM & Mechanical Looseness \\
$3 x$ RPM & Misalignment \\
Less than 1x RPM & Oil Whirl (<1/2 RPM) \& Mechanical Looseness \\
Synchronous (A.C.Line Frequency) & Electrical Problems \\
\hline
\end{tabular}

\subsection{Analisis Perhitungan Frekuensi Kerusakan Bearing}

Defect frequency digunakan untuk mengetahui atau mendiagnosa masalah yang terdapat pada bearing melalui formula yang ada dibawah dengan menginput data-data yang terdapat dalam bearing.

$$
\begin{aligned}
& B P F O=\left(\frac{N b}{2}\right)(S)\left(1-\frac{B d c o s \varphi}{P d}\right) \\
& B P F I=\left(\frac{N b}{2}\right)(s)\left(1+\frac{B d c o s \varphi}{P d}\right) \\
& F T F=\left(\frac{5}{2}\right)\left(1-\frac{B d c o s \varphi}{P d}\right) \\
& B S F=\left(\frac{P d}{2 B d}\right)(S)\left\{1-\left(\frac{B d}{P d}\right)^{2}(\cos \varphi)^{2}\right\}
\end{aligned}
$$

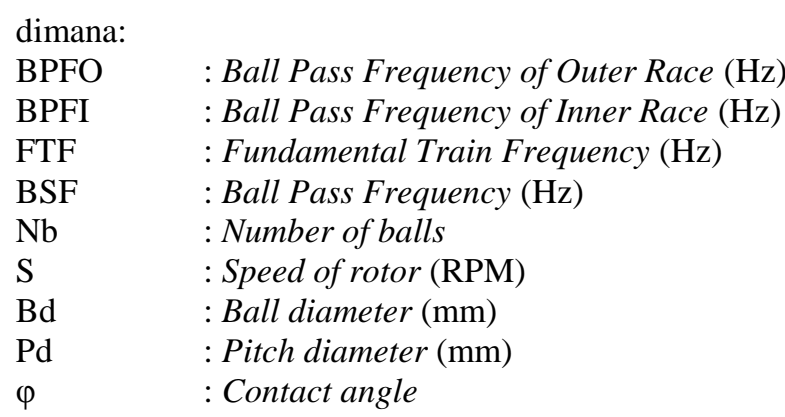

Hasil perhitungan dari defect frequency ini nantinya akan di plot pada spectrum vibrasi.[4]

\section{HASIL DAN PEMBAHASAN}

Berikut ini akan ditampilkan hasil analisis - analisis yang digunakan dalam mencari indikasi kerusakan yang terjadi pada blower 22K-102 Force Draft Fan

\subsection{Pengambilan Data Vibrami dan Analisa Trending dan Spektrum Vibrasi}

Pada bearing outboard dilakukan pengukuran dengan arah axial, dimana pada arah pengukuran ini didapatkan hasil vibrasi diatas batas alert high yaitu sebesar $4,53 \mathrm{~mm} / \mathrm{s} \mathrm{rms}$, berikut hasil dari data pengambilan vibrasi pada Tabel 2 .

Tabel 2. Data Vibrasi Bearing Outboard Arah Axial 


\begin{tabular}{|c|c|c|c|c|c|c|}
\hline Pengukuran & $29 / 01 / 2016$ & $26 / 01 / 2016$ & $\begin{array}{c}25 / 01 / 2016 \\
0: 00\end{array}$ & $\begin{array}{c}22 / 01 / 2016 \\
14: 33\end{array}$ & $\begin{array}{c}22 / 01 / 2016 \\
9: 52\end{array}$ & $\begin{array}{c}21 / 01 / 2016 \\
15: 15\end{array}$ \\
\hline $\begin{array}{c}\text { FAN-OB- } \\
\text { AXIAL }\end{array}$ & 2.38 & 5,64 & 6,78 & 6,64 & 5,67 & 6,48 \\
\hline
\end{tabular}

Dari data diatas diketahui bahwa vibrasi mengalami kenaikan pada tangga 21 Januari 2016, yaitu dengan hasil $6,48 \mathrm{~mm} / \mathrm{s} \mathrm{rms}$, kemudian dari data tersebut dirubah ke trending vibrasi dan kemudian data diolah dengan software omnitrend menjadi spektrum vibrasi.

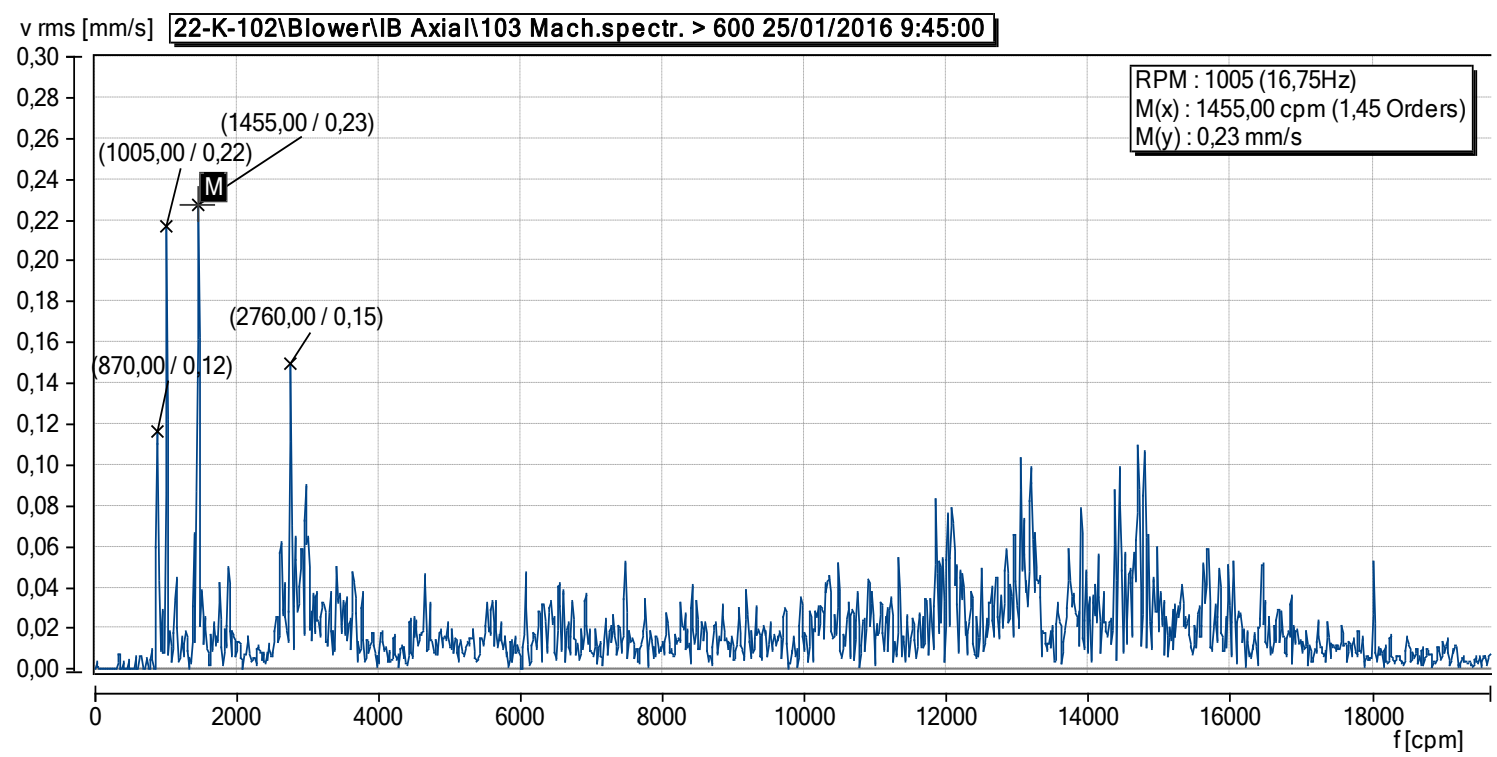

Gambar 3. Spektrum vibrasi pada posisi outboard aksial blower 22-K-102 Force Draft Fan (FDF).

\subsection{Perhitungan Frekuensi Kerusakan Bearing (Defect Frequency)}

Agar kita dapat mengetahui atau mendiagnosa kerusakan yang ada pada beaaring, maka dilakukan perhitungan defect frequency berdasarkan formula atau rumus yang terdapat pada subbab 2.2. Diketahui bearing dengan tipe spherical roller bearing 22224 EK + H3124 + No.FRB 14/215 mempunyai banyaknya ball bearing (Nb) sebanyak 20 dengan motor yang berputar (S) $1005 \mathrm{rpm}$ dengan ball diameter (Bd) 0,905 inch kemudian pitch diameter (Pd) sebesar 6,685 inch dan sudut kontak bearing adalah $10^{\circ} .[5]$

Dari data bearing yang diketahui maka kemudian di-input ke persamaan 1 untuk mengetahui bearing bagian outterrace mengalami kerusakan atau tidak dan didapatkan hasil sebesar $8711,2 \mathrm{cpm}$, kemudian untuk innerrace menggunakan persamaan 2 dan didapatkan nilai BPFI sebesar 11388,7 cpm, selanjutnya untuk lintasan ball bearing atau biasa disebut train dan didapatkan nilai FTF sebesar 435,5 cpm dari persamaan 3. Untuk mengetahui adanya kerusakan ball bearing maka menggunakan persamaan 4 dan hasil BSF adalah 3645,9 cpm. Kemudian dilakukan plotting pada spectrum vibrasi maka didapatkan hasil bahwa tidak adanya kerusakan pada outterrace, innerrace, train, dan ball bearing.[2]

\subsection{Indikasi Kerusakan}

Perhitungan defect frequency vibrasi dan plotting pada spektrum vibrasi tidak ditemukannya gangguan pada outerrace, innerrace, cage, dan rolling element pada bearing outboard aksial blower 22-K-102 Force Draft Fan (FDF). Bisa disimpulkan tingginya getaran bukan dikarenakan kerusakan elemen pada bearing, tetapi dikarenakan adanya looseness.

\subsection{Analisa Perbaikan}

Setelah dilakukan perhitungan dengan defect frequency didapatkan hasil bahwa tidak ada kerusakan pada bearing dan diindikasi bahwa terjadi mechanical looseness maka dilakukan analisa perbaikan, yaitu dengan cara tightening locknut, yaitu dengan cara sebagai berikut.

Pengukuran clearance bearing, didapatkan hasil bahwa bearing mempunyai clearance yang jauh dari batasan pabrik yaitu sebesar $0,05 \mathrm{~mm}$ sedangkan diukur dengan hasil $0,2 \mathrm{~mm}$. Setelah itu dilakukan regreasing bagian clearance bearing dan juga pengencangan ulir bearing, dan didapatkan clearance sebesar 0,05 $\mathrm{mm}$ dan dilakukan running kembali dan didapatkan hasil pada tanggal 29 jnuari 2016 yaitu sebesar 2,38 mm/s rms, hasil ini sudah berada dibawa batas alert high.

\section{KESIMPULAN}


Setelah dilakukan analisa - analisa didapatkan beberapa kesimpulan yang akan dijelaskan sebagai berikut

1. blower 22-K-102 Force Draft Fan (FDF) merupakan blower yang digerakkan oleh motor listrik merek Siemens yang mempunyai kecepatan putar sebesar $1005 \mathrm{rpm}$

2. Penyebab tingginya vibrasi pada pengukuran bearing yaitu dikarenakan terlalu besarnya internal clearance dimana batas toleransi adalah 0,05 sedangkan yang didapatkan pada pengukuran menggunakan feeler adalah sebesar $0,2 \mathrm{~mm}$

3. Diberikan treatment yaitu dengan cara tightening locknut dengan cara pengencangan ulir pada bearing dan penambahan grease pada internal clearance sehingga didapatkan clearance sebesar 0,05 mm yang sudah sesuai dengan batas toleransi dari bearing outboard blower 22224 EK + H3214 + No. FRB 14/215

4. Setelah dilakukan tightening locknut maka dilakukan recheck vibrasi sehingga didapatkan vibrasi yang normal pada pengukuran aksial bearing outboard blower 22224 EK + H3214 + No. FRB 14/215

\section{REFERENSI}

[1] Vebiyanto, Ivan. 2006. Evaluasi Temperatur Reformer Pada Unit 22 Hidrogen Plant Di PT. Pertamina (PERSERO) Unit Pengolahan VI Balongan-Jawa Barat

[2] Graney, Brian P., Starry Ken. 2011. Rolling Element Bearing Analysis. ME Technical Paper. The American Society for Nondesdructive Testing Inc.

[3] Hardjono, R. N., Sukmadi T., Karnoto. 2013. Pemanfaatan Spektrum Vibrasi Untuk Mengindikasikan Kerusakan Motor Induksi Di Pltu Indramayu 3 X 330 MW. Transient Vol. 2. Universitas Diponegoro.

[4] Prasetyo, Gusti. "Mengenal Pengukuran Vibrasi pada Motor dan Pompa". Februari 2016. dunialistrik.blogspot.com

[5] Timken. "Timken Spherical Roller Bearing Catalog". Februari 2016 http://www.timken.com/enus/products/Documents/Timken-Spherical-Roller-Bearing-Catalog.pdf 